\title{
Transduction of Streptomycin Resistance in Proteus mirabilis
}

\author{
BY J. N. COETZEE AND T. G. SACKS \\ Department of Microbiology, University of Pretoria, Pretoria, South Africa
}

(Received 3 May 1960)

\section{SUMMARY}

Five of eleven different temperate Proteus phages are capable of intrastrain transduction of a streptomycin resistance marker. Interstrain transduction of this marker was achieved with three of the five phages. Nuclear segregation and phenomic lag may both be involved in the delay in phenotypic expression of streptomycin resistance. The one transducing phage investigated appears to possess a normal phage genome in that transductant colonies are lysogenic and show lysogenic conversion, at multiplicities of phage input of less than 0.02 , and under conditions where secondary infection on the plates can be excluded. However, under these conditions a few transductant clones were encountered which were not lysogenic. This indicates that the transducing and lysogenizing functions of this phage may be divorced from each other. Ultraviolet irradiation has a differential effect on its transducing and plaque-forming abilities.

\section{INTRODUCTION}

Coetzee (1958) demonstrated that many sewage phages isolated by lysis of different strains of Proteus mirabilis are also lytic for $\boldsymbol{P}$. vulgaris strains and vice versa. To show that $\boldsymbol{P}$. mirabilis and $\boldsymbol{P}$. vulgaris possess genetic homologies and are varieties of a single genus ( $P$. hauseri), the existence of some form of genetic exchange between them was sought. Bacteriophage-mediated genetic exchange of biochemical markers was tried (Coetzee, unpublished). These experiments were unsuccessful, possibly because the phages used were too virulent. With the discovery of a series of temperate Proteus phages (Coetzee \& Sacks, 1959) fresh attempts at transduction were made. The restricted host range of these phages has thwarted the realization of our original objective but we could report (Coetzee \& Sacks, 1960a) two intrastrain transducing systems in $\boldsymbol{P}$. mirabilis, employing streptomycin resistance as marker.

The object of this paper is to report three additional Proteus mirabilis transducing systems and the occurrence of interstrain transduction. Because all the $P$. mirabilis strains used have identical biochemical reactions, natural biochemical markers could not be used in the three interstrain systems available. We have not been able to isolate mutants with biochemical markers or auxotrophic strains, and have confined our efforts to the streptomycin resistance marker. Once the problem of phenotypic delay is overcome, resistance to $1000 \mu \mathrm{g}$. streptomycin $/ \mathrm{ml}$. is a very satisfactory genetic marker. 


\section{METHODS}

Media. The composition of the MacConkey-type agar and the broth employed have been described (Coetzee \& Sacks, 1960b). The MacConkey type soft agar differed from the MacConkey-type agar in that it contained $0.7 \%(\mathrm{w} / \mathrm{v})$ instead of $1.7 \%(\mathrm{w} / \mathrm{v})$ agar. In some experiments $2 \%(\mathrm{w} / \mathrm{v})$ sodium citrate was added to the media. The MacConkey-type streptomycin agar was made by adding the necessary amount of streptomycin sulphate to the molten agar at $45^{\circ}$. Deoxyribonuclease, obtained from Seravac Laboratories, Cape Town, was used at a concentration of $40 \mu \mathrm{g} / \mathrm{ml}$.

Organisms and phages. A series of 11 different phages isolated from lysogenic strains of Proteus (Coetzee \& Sacks, 1959) were employed. Phages 12/57, 49/F 7, 50/F7 and 54/F7 were obtained by ultraviolet irradiation of Proteus strains 12, 49,50 and 54 respectively. The indicator organism for the phage obtained from Proteus 12 was Proteus 57, and the indicator organism for phages from Proteus 49, 50 and 54 was Proteus F7. Phages $34 / 13$ and 36/13 were present in the supernatant fluids of 10-day broth cultures of Proteus 34 and 36, respectively. Proteus 13 was the indicator organism for both these phages. Phages $\frac{6}{24} / 6, \frac{12}{57} / 57, \frac{14}{20} / 14, \frac{14}{20} / 20$ and $\frac{24}{25} / 14$ were present in the supernatant fluids of 10-day broth cultures of 6 and 24, 12 and 57, 14 and 20,14 and 20,24 and 25, respectively. The indicator organisms for these phages were Proteus strains 6, 57, 14, 20 and 14, respectively. The phages fail to clear broth cultures of their indicator organisms (Coetzee \& Sacks, unpublished). Phages $34 / 13$ and $36 / 13$ are related serologically as are phages $\frac{14}{20} / 14$ and $\frac{24}{25} / 14$. Phage $12 / 57$ is not antigenically related to these phages (Coetzee \& Sacks, unpublished).

Proteus strains were maintained on nutrient agar slopes at $4^{\circ}$. Proteus mutants resistant to streptomycin were selected by plating $c .10^{11}$ cells on MacConkey agar containing $1000 \mu \mathrm{g}$. streptomycin $/ \mathrm{ml}$. These mutants, which are resistant to $1000 \mu \mathrm{g}$. streptomycin/ml., are marked by str-r following the identifying number of the organism. Organisms $113,193,57$ and 13 are biochemically typical and identical Proteus mirabilis strains. The A phases (Belyavin, 1951) of 113 and 57 (or 57 str-r) do not swarm into each other and thus show a positive Dienes phenomenon (Dienes, 1947). It is concluded that they differ antigenically (Krikler, 1953). Organisms 193 and 13 (or 13 str-r) can be distinguished by the fact that they show different lytic patterns to a series of Proteus typing phages (Coetzee \& Sacks, unpublished).

Preparation of phage lysates. Phage lysates with plaque-forming titres of $c .10^{10} /$ ml. were made by the modification (Adams, 1956) of the method of Hershey, Kalmanson \& Bronfenbrenner (1943). Phages were propagated on the indicator organism or on its streptomycin resistant mutant. The latter phages are identified by the letters str-r appearing after the number of the indicator strain. Phage lysates were sterilized by mixing with $0 \cdot 1$ vol. of chloroform. Other phage techniques used have been described by Adams (1956). Irradiation of phage lysates was by a $30 \mathrm{~W}$. Hanovia sterilamp which delivers more than $80 \%$ of its output at a wave-length of $2537 \AA$. Lysates were irradiated in broth in thin layers in Petri dishes at a vertical distance of $50 \mathrm{~cm}$. from the lamp (10 ergs $/ \mathrm{mm} .{ }^{2} / \mathrm{sec}$.). The contents of the Petri dishes were continuously agitated. During irradiation experiments the intensity of visible light was kept sufficiently low to avoid photoreactivation. 
Transduction techniques. Phage active on the wild-type was grown successively on the corresponding streptomycin resistant mutant at least three times before transduction experiments were attempted. Transduction experiments were done as follows: three tubes, each containing $0.5 \mathrm{ml}$. of an aerated overnight culture of the potential recipient (titre $2 \times 10^{9} / \mathrm{ml}$.) were centrifuged to clarity and the supernatant decanted. One $\mathrm{ml}$. of the phage lysate of the streptomycin resistant strain (titre c. $5 \times 10^{9} / \mathrm{ml}$.) was then mixed with the deposit in one of the tubes. One $\mathrm{ml}$. of phage from the wild type donor (streptomycin sensitive indicator strain) of about the same titre was mixed with the deposit in the second tube and $1 \mathrm{ml}$. of broth was added to the deposit in the third tube. A fourth tube containing $1 \mathrm{ml}$. of phage suspension derived from the streptomycin resistant mutant served as the phage sterility control. After $15 \mathrm{~min}$. adsorption at $37^{\circ}, 0 \cdot 1 \mathrm{ml}$. of the infected bacteria and the controls was spread to dryness on MacConkey agar plates. These plates were kept at $37^{\circ}$ for $3 \mathrm{hr}$., and were then carefully overlayed with $5 \mathrm{ml}$. of MacConkey soft agar at $45^{\circ}$ containing streptomycin sulphate to give a concentration of $c .1000 \mu \mathrm{g}$. streptomycin $/ \mathrm{ml}$. in the plates. After incubation for a further $24 \mathrm{hr}$. at $37^{\circ}$, the number of colonies appearing was recorded. Reconstruction experiments with known numbers of streptomycin resistant cells have shown that the $3 \mathrm{hr}$. old microcolonies are not disturbed by overlaying with the soft streptomycin agar. Lysates yielding positive results by the above test were mixed with either varying amounts of phage antiserum or deoxyribonuclease at $37^{\circ}$ for $1 \mathrm{hr}$. The effect of these procedures was noted on the plaque-forming titre of the lysate and on the number of transductants produced.

Bacterial colony counts on MacConkey agar on samples from the adsorption tube measured bacterial survival.

Adsorption experiments of phage on bacteria were done as previously described (Coetzee, 1960).

Association of transduction and lysogenization. To investigate the association between transduction and lysogenization the technique of the transduction experiments was modified. One ml. of each of a series of doubling dilutions of phage from streptomycin resistant donors was added (in duplicate) to the usual constant number of recipient cells. The phage from the streptomycin sensitive donor at a multiplicity of input of 10 , contained in $0.5 \mathrm{ml}$. was added to each of the one series of tubes and $0.5 \mathrm{ml}$. broth to each of the other series. In these experiments the possibility of lysogenization of the transductants by phage liberated on the plates from the background of phage-infected cells must be considered. With phage 34/13 str-r this possibility can be excluded by taking advantage of the fact that like phage $\mathrm{P} 1$ (Adams \& Luria, 1958) it is dependent on $\mathrm{Ca}^{++}$for adsorption (Coetzee \& Sacks, unpublished). The infected cells were centrifuged after the adsorption period and resuspended in $1.0 \mathrm{ml}$. of broth containing $2 \%$ sodium citrate. This suspension was plated on to MacConkey agar plates, containing $2 \%$ sodium citrate, in the presence of potent phage antiserum. After $3 \mathrm{hr}$. incubation the plates were overlayed with MacConkey soft agar containing $2 \%$ sodium citrate and streptomycin. These procedures remove unadsorbed phage, neutralize phage liberated on the plates, and prevent adsorption of phage not inactivated. Transductant colonies were picked off the plates and suspended in $1.0 \mathrm{ml}$. of broth containing $2 \%$ sodium citrate. These suspensions were immediately plated, with phage antiserum, on to 
MacConkey agar plates containing $2 \%$ sodium citrate, and were also inoculated into citrate broth. The presence of liberated phage in these broth cultures after overnight incubation was determined by the production of plaques on Proteus 13. Single colonies from the last-mentioned citrate MacConkey agar plates were inoculated into plain broth, incubated overnight and titrated on Proteus 13 and streaked on MacConkey agar containing $0.001 \mathrm{~N}-\mathrm{Ca}^{++}$, and spotted at four sites with phage 34/13 str-r. The efficiency of the method used to eliminate secondary infection occurring on the plates was tested in reconstruction experiments. Proteus 13 was mixed with the non-transducing phage (34/13) at multiplicities of input ranging from 10 to 0.001 . Non-adsorbed phage was removed by centrifuging, and the deposit was resuspended in broth containing sodium citrate. $0 \cdot 1 \mathrm{ml}$. was plated with phage antiserum on to MacConkey agar plates containing sodium citrate. Suspensions of phage susceptible streptomycin resistant mutants diluted to yield c. 50 colonies per plate were then spread on all the plates. After $3 \mathrm{hr}$. incubation the plates were overlayed with soft agar containing streptomycin and sodium citrate. Forty entire colonies from each plate were streaked on MacConkey agar and phage 34/13 spotted at four sites along the streak.

\section{RESULTS}

Results of tranduction experiments are summarized in Table 1. These indicate that five of eleven different phage lysates examined are capable of intrastrain transduction of the streptomycin resistance marker and three of interstrain transduction of the same marker. Unsuccessful results in Table 1 represent failures using as

Table 1. Summary of results of transduction experiments

\begin{tabular}{|c|c|c|c|c|c|}
\hline \multirow[b]{2}{*}{ Phage } & \multicolumn{5}{|c|}{ Recipient Proteus } \\
\hline & 57 & 13 & 14 & 113 & 103 \\
\hline $12 / 57$ str-r & + & $\mathbf{0}$ & $\mathbf{0}$ & + & $\mathbf{0}$ \\
\hline 34/13 str-r & $\mathbf{0}$ & + & 0 & $\mathbf{0}$ & + \\
\hline$\frac{1}{2} \frac{4}{0} / 14 s t r-r$ & $\mathbf{0}$ & 0 & + & 0 & 0 \\
\hline$\frac{24}{25} / 14 s t r-r$ & $\mathbf{0}$ & 0 & + & $\mathbf{0}$ & 0 \\
\hline \multirow[t]{2}{*}{ 36/13 str-r } & $\mathbf{0}$ & + & $\mathbf{0}$ & $\mathbf{0}$ & + \\
\hline & Fr & 57 & 20 & 6 & \\
\hline 49/F7 str-r & - & $\mathbf{0}$ & 0 & $\mathbf{0}$ & \\
\hline $54 / \mathrm{Fr}$ str-r & $\rightarrow$ & $\mathbf{0}$ & 0 & 0 & \\
\hline$\frac{12}{57} / 57$ str $-r$ & 0 & - & $\mathbf{0}$ & 0 & \\
\hline$\frac{1}{2} \frac{4}{0} / 20 s t r-r$ & 0 & $\mathbf{0}$ & - & $\mathbf{0}$ & \\
\hline $50 / \mathrm{Fr}$ str-r & - & $\mathbf{0}$ & $\mathbf{0}$ & $\mathbf{0}$ & \\
\hline$\frac{6}{24} / 6$ str $-r$ & $\mathbf{0}$ & $\mathbf{0}$ & $\mathbf{0}$ & - & \\
\hline
\end{tabular}

potential recipients the streptomycin sensitive parental strain as host. While not presented in the table, negative results were also obtained with the few other available strains to which the phages adsorb. Adsorption experiments of transducing phage to recipient organisms reveal that more than $95 \%$ adsorption occurs in 15 min. Table 2 shows the results of a typical experiment with phage 12/57 str-r. In the numerous 
experiments done with the various systems, platings from cells infected with phage grown on streptomycin sensitive donors never showed any colonies, while on only five occasions were single colonies (spontaneous mutants) ever observed in platings

Table 2. Results of transduction experiments with phage 12/57 str-r

\begin{tabular}{|c|c|c|c|c|c|c|c|}
\hline & Tube 1 & Tube 2 & Tube 3 & Tube 4 & Tube 5 & Tube 6 & $\begin{array}{c}\text { Transduction } \\
\text { rate/phage } \\
\text { particle } \\
\text { adsorbed }\end{array}$ \\
\hline Phage 12/57 str-r & $1.0 \mathrm{ml}$ & $\mathbf{0}$ & $\mathbf{0}$ & $1.0 \mathrm{ml}$. & $\mathbf{0}$ & $\mathbf{0}$ & - \\
\hline Phage 12/57 & $\mathbf{0}$ & $1.0 \mathrm{ml}$ & $\mathbf{0}$ & $\mathbf{0}$ & $\mathbf{0}$ & $\mathbf{0}$ & - \\
\hline Broth & $\mathbf{0}$ & $\mathbf{0}$ & $1.0 \mathrm{ml}$ & $\mathbf{0}$ & 0 & 0 & - \\
\hline Phage 12/57 str-r+DNase & 0 & $\mathbf{0}$ & 0 & $\mathbf{0}$ & $1.0 \mathrm{ml}$ & $\mathbf{0}$ & - \\
\hline $\begin{array}{l}\text { Phage 12/57 str- } r+\text { anti- } \\
\text { phage serum }\end{array}$ & $\mathbf{0}$ & $\mathbf{0}$ & $\mathbf{0}$ & $\mathbf{0}$ & 0 & $1.0 \mathrm{ml}$. & - \\
\hline Recipient bacteria & $1 \times 10^{9}$ & $1 \times 10^{9}$ & $1 \times 10^{9}$ & $\mathbf{0}$ & $1 \times 10^{9}$ & $1 \times 10^{9}$ & - \\
\hline $\begin{array}{l}\text { No. of colonies } \\
\text { (Recipient strain 57) }\end{array}$ & 194 & $\mathbf{0}$ & 0 & $\mathbf{0}$ & 190 & 0 & $2 \times 10^{-6}$ \\
\hline $\begin{array}{l}\text { No. of colonies } \\
\text { (recipient strain 113) }\end{array}$ & 20 & $\mathbf{0}$ & $\mathbf{0}$ & $\mathbf{0}$ & 21 & $\mathbf{0}$ & $2 \cdot 1 \times 10^{-7}$ \\
\hline $\begin{array}{l}\text { Plaque-forming titre on } \\
\text { strain } 57\end{array}$ & $\begin{array}{l}1 \times 10^{9} / \\
\text { ml. }\end{array}$ & $\begin{array}{l}2 \times 10^{9} / \\
\text { ml. }\end{array}$ & - & $\begin{array}{l}1 \times 10^{\circ} / \\
\text { ml. }\end{array}$ & $\begin{array}{l}1 \times 10^{\circ} / \\
\mathrm{ml} .\end{array}$ & $\begin{array}{l}4 \times 10^{3} / \\
\mathrm{ml} .\end{array}$ & 一 \\
\hline
\end{tabular}

Tube 5 contained $1.0 \mathrm{ml}$. phage $12 / 57$ str-r previously incubated with $40 \mu \mathrm{g}$. DNase at $37^{\circ}$ for $1 \mathrm{hr}$.

Tube 6 contained $1.0 \mathrm{ml}$. phage $12 / 57$ str-r previously incubated with anti-phage serum at $37^{\circ}$ for $1 \mathrm{hr}$.

Plaque-forming titres determined just prior to mixing phage and recipient.

No. of colonies refers to the no. arising on MacConkey-type agar plates containing $1000 \mu \mathrm{g} . / \mathrm{ml}$. streptomycin, after plating $0 \cdot 1 \mathrm{ml}$.

Transduction rates were calculated on the basis of the demonstrated $95 \%$ adsorption.

Table 3. Results obtained in typical experiments with transducing phages other than 12/57 str-r

\begin{tabular}{|c|c|c|c|c|}
\hline Phage & $\begin{array}{l}\text { Recipient } \\
\text { strain }\end{array}$ & $\begin{array}{c}\text { Plaque-forming } \\
\text { titre } / \mathrm{ml} \text {. }\end{array}$ & $\begin{array}{l}\text { No. of colonies } \\
\text { on MacConkey } \\
\text { agar containing } \\
1000 \mu \mathrm{g} . / \mathrm{ml} . \\
\text { streptomycin }\end{array}$ & $\begin{array}{c}\text { Transduction rate/ } \\
\text { phage particle adsorbed }\end{array}$ \\
\hline $34 / 13$ str-r & 13 & $1 \times 10^{\circ}$ & 10 & $1.1 \times 10^{-7}$ \\
\hline $34 / 13$ str-r & 193 & $1 \times 10^{9}$ & 532 & $5.6 \times 10^{-6}$ \\
\hline $36 / 13$ str-r & 18 & $6 \times 10^{\circ}$ & $\mathbf{3 3}$ & $5.8 \times 10^{-8}$ \\
\hline $36 / 13$ str-r & 193 & $6 \times 10^{9}$ & 102 & $1.8 \times 10^{-7}$ \\
\hline$\frac{1}{2} \leqslant / 14$ str- $r$ & 14 & $5 \times 10^{10}$ & $\mathbf{5 0}$ & $1.1 \times 10^{-8}$ \\
\hline$\frac{2}{25} / 14 s t r-r$ & 14 & $5 \times 10^{10}$ & 75 & $1.6 \times 10^{-8}$ \\
\hline
\end{tabular}

$1 \mathrm{ml}$. of phage suspension mixed with a deposit of $1 \times 10^{\circ}$ recipient bacteria. $0.1 \mathrm{ml}$. from adsorption tubes plated. Transduction rates calculated on the basis of the demonstrated $95 \%$ adsorption.

from uninfected recipient cells. The transducing ability of a lysate was not affected by prior treatment with deoxyribonuclease, and bacteriophage was implicated as the genetic vector by abolition of transductants in experiments using a phage lysate previously treated with antiphage serum. The phage lysate from streptomycin resistant cells never produced colonies when plated on MacConkey-type agar.

Results obtained with phages other than 12/57 str-r are summarized in Table 3. 
Intra- and interstrain transduction rates per phage particle adsorbed cannot be compared. This is due to differences in the lytic response of the recipient bacteria concerned.

The effect of ultraviolet irradiation on the transducing and plaque-forming ability of phage lysates $34 / 13$ str-r is illustrated in Fig. 1. This reveals that the transducing ability of phage $34 / 13$ str-r was more resistant to ultraviolet irradiation than its lytic activity. Phage 12/57 str-r (the only other phage investigated) has similar

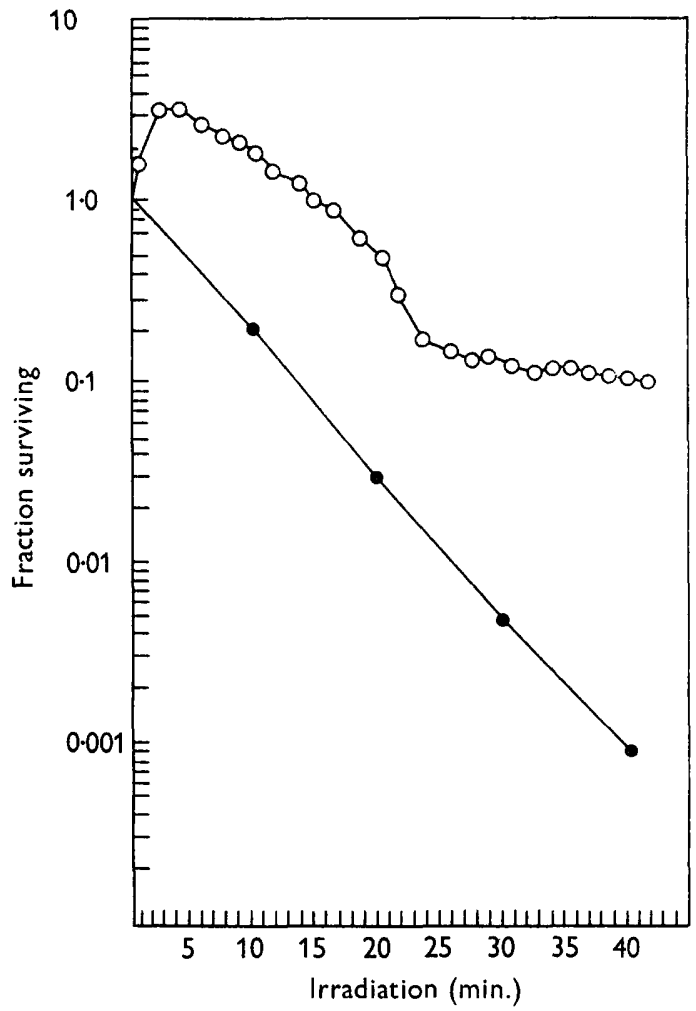

Fig. 1. Effect of ultraviolet irradiation on plaque-forming and transducing ability of phage 34/13 str-r. A lysate of phage 34/13 str-r (plaque-forming titre $1 \times 10^{9} / \mathrm{ml}$.) was irradated in broth at $10 \mathrm{ergs} / \mathrm{mm} .{ }^{2} / \mathrm{sec}$. At intervals, aliquots were removed and used in transduction experiments with Proteus 13 as recipients The plaque-forming ability of the aliquots was"also determined. Experiments were conducted in the dark. - $\mathrm{O}-$, Transducing activity; - -

properties. No explanation for the initial rise in the transduction curve can be given. Similar findings have been recorded for other transducing systems (Garen \& Zinder, 1955; Holloway \& Monk, 1959; Loutit, 1959).

The phenomenon of delay in expression of transduced streptomycin resistance was investigated by plating $0.1 \mathrm{ml}$. of the transducing mixture and the controls at intervals directly on to MacConkey agar plates containing different concentrations of streptomycin. Results are presented in Table 4. Because of lysis of some recipient bacteria and because infection may not be simultaneous this method does not allow the accurate determination of the number of divisions required for expres- 
sion of resistance to $1000 \mu \mathrm{g}$. streptomycin $/ \mathrm{ml}$. The results show, however, that resistance can be expressed after a doubling of the population surviving after $15 \mathrm{~min}$. More transductants are recovered earlier on low concentrations of streptomycin indicating that complete phenotypic expression of the transduced character takes place gradually. Similar results were encountered by Watanabe \& Watanabe

Table 4. Results of a transduction experiment with phage 12/57 str-r and recipient strain 57 to demonstrate the properties of phenotypic delay in the expression of streptomycin resistance

\begin{tabular}{|c|c|c|c|c|c|c|}
\hline \multirow{2}{*}{$\begin{array}{l}\text { Min. after } \\
\text { mixing } \\
\text { phage } \\
\text { and } \\
\text { recipient } \\
\text { at } 37^{\circ}\end{array}$} & \multirow{2}{*}{$\begin{array}{c}\text { Viable } \\
\text { bacteria } \\
\text { per ml. }\end{array}$} & \multicolumn{5}{|c|}{$\begin{array}{l}\text { No. of colonies on MacConkey agar containing streptomycir } \\
\qquad(\mu \mathrm{g} . / \mathrm{ml} .)\end{array}$} \\
\hline & & 125 & 250 & 500 & 1000 & 2000 \\
\hline 15 & $3 \cdot 1 \times 10^{6}$ & 0 & 0 & $\mathbf{0}$ & 0 & 0 \\
\hline 60 & $3.5 \times 10^{6}$ & 15 & 9 & 2 & 0 & 0 \\
\hline 90 & $6.5 \times 10^{6}$ & 28 & 17 & 8 & $\mathbf{2}$ & $\mathbf{0}$ \\
\hline 120 & $9 \cdot 0 \times 10^{6}$ & $\mathbf{5 4}$ & 36 & $\mathbf{3 4}$ & 26 & 9 \\
\hline 150 & $1.3 \times 10^{7}$ & 198 & 165 & 143 & 112 & 61 \\
\hline 180 & $2.3 \times 10^{7}$ & 308 & 217 & 181 & 170 & 121 \\
\hline 240 & $6.0 \times 10^{7}$ & 621 & 631 & 497 & 516 & 412 \\
\hline 300 & $1.5 \times 10^{8}$ & 932 & 912 & 820 & 844 & 722 \\
\hline 360 & $2.4 \times 10^{8}$ & 1192 & 1020 & 932 & 964 & 934 \\
\hline
\end{tabular}

A deposit of $1 \times 10^{7}$ bacteria was infected with $1.0 \mathrm{ml}$. of phage $12 / 57$ str- $r$ at a multiplicity of input of 5. Six identical adsorption tubes were pooled to provide sufficient transducing mixture for inoculation of plates with $0.1 \mathrm{ml}$.

Table 5. Results of a reconstruction experiment to test for lysogenization of colonies by phage liberated on transduction plates

$1.0 \mathrm{ml}$. of appropriate dilutions of phage 34/13 added to deposits of $c .1 \times 10^{9}$ Proteus 13 . After adsorption for $15 \mathrm{~min}$. tubes were centrifuged and deposits resuspended in $1.0 \mathrm{ml}$. citrate broth. $0.1 \mathrm{ml}$. plated, with phage antiserum, on citrate MacConkey agar platet. c. 50 cells of Proteus 13 str-r inoculated on to each plate. After $3 \mathrm{hr}$. incubation plates overlayed with agar containing citrate and streptomycin.

$\begin{array}{ccc}\text { M.I. } & \begin{array}{c}\text { No. of colonies } \\ \text { tested }\end{array} & \begin{array}{c}\text { No. of phage } \\ \text { susceptible } \\ \text { colonies }\end{array} \\ 10 & 40 & 40 \\ 1 & 40 & 40 \\ 0 \cdot 1 & 40 & 40 \\ 0 \cdot 01 & 40 & 40 \\ 0 \cdot 001 & 40 & 40\end{array}$

Colonies present after $18 \mathrm{hr}$.-incubation at $37^{\circ}$ tested for phage susceptibility, by picking off entire colony, streaking on plain MacConkey plates and spotting with phage 34/13. M.I. $=$ multiplicity of phage input.

(1959) for streptomycin indifference transduction in Salmonella typhimurium and by Alexander \& Leidy (1953) for streptomycin resistance transformation in Haemophilus influenzae. Cells of Proteus mirabilis contain from 1 to 4 nuclei (Coetzee \& Sacks, $1960 c$ ). Streptomycin resistance is recessive to sensitivity in Escherichia coli (Lederberg, 1951). If this also applies to Proteus, the time required for segregation 
of a homonucleate cell (Newcombe \& Hawirko, 1949) may be one factor involved in the delay in phenotypic expression. The phenotypic expression of a different gene may have to await the exhaustion of pre-existing material in a cell; that this phenomic delay (Lamanna \& Mallette, 1953) may be an additional factor involved is indicated by the fact that the transition from partial to complete resistance is lengthy and gradual.

All transductant clones are perfectly stable for their newly acquired character and although the morphological phase $B$ (Belyavin, 1951) is commonest, all other phases, except the $\mathbf{R}$ variants (Coetzee, 1959), are seen.

Table 6. Results of an experiment with phage 34/13 str-r to show the relationship between multiplicity of infection, lysogenization and transduction

Deposit from adsorption tubes resuspended in broth containing $2 \%$ sodium citrate. $0.2 \mathrm{ml}$. plated together with $0.2 \mathrm{ml}$. anti-phage serum on to MacConkey agar containing $2 \%$ sodium citrate. After $3 \mathrm{hr}$. incubation, plates overlayed with agar containing citrate and streptomycin. Colonies present after $18 \mathrm{hr}$. incubation at $37^{\circ}$ tested for spontaneous liberation of phage and phage susceptibility. Denominators indicate no. of clones tested. M.I. = Multiplicity of phage input.

$1 \cdot 0 \mathrm{ml}$. of doubling dilutions of transducing phage (plaque-forming titre $1 \times 10^{10} / \mathrm{ml}$.) added to deposits of $1 \times 10^{\circ}$ of strain 13 and mixed with

\begin{tabular}{|c|c|c|c|c|}
\hline \multirow{2}{*}{\multicolumn{2}{|c|}{$\begin{array}{l}0.5 \mathrm{ml} \text {. wild phage } \\
\text { (titre } 2 \times 10^{10} / \mathrm{ml} \text {.) }\end{array}$}} & \multicolumn{3}{|c|}{$0.5 \mathrm{ml}$. broth } \\
\hline & & & \multicolumn{2}{|c|}{ Transductant clones } \\
\hline $\begin{array}{l}\text { M.I. } \\
10 \text { plus }\end{array}$ & $\begin{array}{l}\text { Total no. } \\
\text { transluctant } \\
\text { clones }\end{array}$ & M.I. & Total no. & $\begin{array}{l}\text { No. lysogenic and } \\
\text { phage insusceptible }\end{array}$ \\
\hline 10 & $>1500$ & 10 & $>1500$ & $30 / 30$ \\
\hline 5 & $>1500$ & 5 & $>1500$ & $\mathbf{3 0 / 3 0}$ \\
\hline $2 \cdot 5$ & $>1500$ & $2 \cdot 5$ & $>1500$ & $30 / 30$ \\
\hline $1 \cdot 3$ & $>1500$ & $1 \cdot 3$ & $>1500$ & $\mathbf{3 0 / 3 0}$ \\
\hline $0 \cdot 6$ & 982 & $0 \cdot 6$ & 1040 & $30 / 30$ \\
\hline $0 \cdot 3$ & 520 & $0 \cdot 3$ & 542 & $30 / 30$ \\
\hline $0 \cdot 2$ & 176 & $0 \cdot 2$ & 189 & $30 / 30$ \\
\hline $0 \cdot 1$ & 128 & $0 \cdot 1$ & 114 & $30 / 30$ \\
\hline 0.04 & 71 & 0.04 & 64 & $30 / 30$ \\
\hline $0 \cdot 02$ & 41 & 0.02 & 36 & $18 / 20 *$ \\
\hline 0.01 & 18 & 0.01 & 20 & $15 / 15$ \\
\hline 0.005 & 13 & 0.005 & 13 & $8 / 10^{*}$ \\
\hline $0 \cdot 002$ & 4 & $0 \cdot 002$ & 6 & $5 / 6 *$ \\
\hline 0.001 & 1 & $0 \cdot 001$ & 3 & $3 / 3$ \\
\hline $0 \cdot 0005$ & $\mathbf{0}$ & 0.0005 & 0 & - \\
\hline $0 \cdot 0002$ & $\mathbf{0}$ & 0.0002 & $\mathbf{0}$ & - \\
\hline 0.0001 & 0 & $0 \cdot 0001$ & 0 & - \\
\hline 0.00005 & 0 & 0.00005 & 3 & $3 / \mathbf{3}$ \\
\hline
\end{tabular}

*'These 5 non-lysogenic clones were phage susceptible.

No abortive transductants (Stocker, 1956) were encountered. This may be due to the possibility that streptomycin resistance is recessive to sensitivity and also to the fact that there is a delay in phenotypic expression of streptomycin resistance. Watanabe \& Watanabe (1959) advanced similar reasons for their failure to observe abortive transductants in the transduction of streptomycin resistance in the Salmonella typhimurium system. 
Results of experiments to demonstrate the relationship between lysogenization and transduction are presented in Tables 5 and 6 . In the reconstruction experiment (Table 5), entire colonies were streaked on the plates prior to multiple spotting with phage. It is unlikely that these results can all be ascribed to the presence of non-lysogenic segregants. It is concluded that under conditions prevailing in these experiments secondary infection resulting in lysogenization of colonies arising on the plates does not occur. Results in Table 6 indicate that the yield of transductants is roughly proportional to phage input and is insensitive to assistance by nontransducing phage; and that the vast majority of transductant clones, even at low multiplicities of input, are lysogenic and liberate phage spontaneously. No discrepancies were noted between the two broth cultures tested for each clone. The lysogenic transductant clones are not only phage insusceptible but also fail to adsorb homologous phage. This phenomenon, which is due to lysogenic conversion (Coetzee, 1960), has precluded the use of these transductants as donors for further experiments and has also prevented the use of lysogenized cells as recipients. The rare non-lysogenic transductants discovered were sensitive to homologous phage. No defective lysogenic transductant colonies were encountered.

Transduction experiments attempted with phage liberated spontaneously by the lysogenic transductant clones (plaque-forming titre $1 \times 10^{6} / \mathrm{ml}$.) were unsuccessful.

\section{DISCUSSION}

In the intrastrain transduction previously described (Coetzee \& Sacks, 1960a), donor and recipient cells were isogenic except for the marker in question. The interstrain transduction achieved here shows that the transferred genetic fragment is also capable of integration in a different genome. The restricted host range of the phages has prevented any inter-genus hybridization of the kind achieved by Lennox (1955) with phage P1.

Five of eleven different Proteus phages are capable of transducing the str-r marker. This indicates a position similar to that in Salmonella where many temperate phages can transduce (Edwards, Davis \& Cherry, 1955). A different situation exists in Escherichia coli where only two phages (which are also related serologically) are competent in general transduction (Jacob, 1955).

The transduction of only one marker has been investigated in the various Proteus systems described. The title of general or common transduction as exemplified by Zinder \& Lederberg's (1952) original system using Salmonella typhimurium and phage P22 and later extended to Escherichia coli by the use of phage P1 (Lennox, 1955; Jacob, 1955) can therefore not be applied to these processes at this stage. The rates of transduction per phage particle are of the same order as those found in general transduction. However, unlike transducing phages P1, and possibly P22 (Starlinger, 1958; Stocker, 1959) transducing phage 34/13 str-r appears to possess a complete phage genome, since at multiplicities of phage input of 0.02 and less, most transductant clones are lysogenic and show conversion. The rare exceptions encountered indicate that the lysogenizing and transducing properties of this phage are functions which may be divorced. Separation of these activities of phage P22 has been reported under a variety of conditions (Hartman, 1957). The differential effect which ultraviolet irradiation of phage 34/13 str-r has on its 
plaque-forming and transducing abilities affords a further example of how phage activities may be divorced from each other. While the failure to transduce the streptomycin resistance marker with phage liberated spontaneously by the lysogenic transductants is probably due to the low multiplicity of phage input, it also indicates that the high-frequency tranduction system described by Morse, Lederberg $\&$ Lederberg $(1956 a, b)$ for the $\lambda$-Gal phage system in $E$. coli is not being encountered, The $\lambda$-Gal phage system also differs from the Proteus transduction mechanism described here in that only induced lysogenic $\boldsymbol{E}$. coli yield active lysates. Further differentiation from the $\lambda$ system may be made when more genetic markers are discovered in Proteus.

Acknowledgement is made to Mrs M. Riley and Miss M. L. Fischer for technical assistance rendered. The senior author is in receipt of a grant from the South African Council for Scientific and Industrial Research.

\section{REFERENCES}

Adams, M. H. (1956). Methods of study of bacterial viruses. Meth. Med. Res. 2, 1.

Adams, J. N. \& LuRia, S. E. (1958). Transduction by bacteriophage P1: abnormal phage function of the transducing particles. Proc. nat. Acad. Sci., Wash. 44, 590.

Alexander, H. E. \& Leidy, G. (1953). Induction of streptomycin resistance in sensitive Haemophilus influenzae by extracts containing deoxyribonucleic acid from resistant Haemophilus influenzae. J. exp. Med. 97, 17.

Belyavin, G. (1951). Cultural and serological phases of Proteus vulgaris. J. gen. Microbiol. 5, 197.

Coetzee, J. N. (1958). The characterization of a series of Proteus bacteriophages. S. Afr. J. Lab. clin. Med. 4, 147.

Coetzee, J. N. (1959). Some properties of a morphological variant of a strain of Proteus vulgaris. S. Afr. J. lab. clin. Med. 5, 16.

Coetzee, J. N. (1960). Lysogenic conversion in the genus Proteus. Nature, Lond. (in the Press).

Coetzee, J. N. \& Sacks, T. G. (1959). Lysogeny in the genus Proteus. Nature, Lond. 184, 1340.

Coetzee, J. N. \& Sacks, T. G. (1960a). Intrastrain transduction in Proteus mirabilis. Nature, Lond. 185, 869.

Coetzee, J. N. \& SaCks, T. G. (1960b). Morphological variants of Proteus hauseri. J. gen. Microbiol. 23, 209.

Coetzee, J. N. \& SAcks, T. G. $(1960 c)$. The late sucrose fermenting property of Proteus mirabilis. S. Afr. J. lab. clin. Med. 6, 49.

Drenes, L. (1947). Further observations on the reproduction of bacilli from large bodies in Proteus cultures. Proc. Soc. exp. Biol., N.Y. 66, 97.

Edwards, P. R., Davis, B. R. \& Cherry, W. B. (1955). Transfer of antigens by phage lysates with particular reference to the $l$, w antigens of Salmonella. J. Bact. 70, 279 .

Garen, A. \& Zinder, N. D. (1955). Radiological evidence for partial genetic homology between bacteriophage and host bacteria. Virology, 1, 347.

Hartman, P. E. (1957). Transduction: a comparative review. Symposium-The Chemical Basis of Heredity, 1st ed., p. 408. Ed. W. D. McElroy \& B. Glass. Baltimore: The Johns Hopkins Press.

Hershey, A. D. Kalmanson, G. \& Bronfenbrenner, J. (1943). Quantitative methods in the study of the phage-antiphage reaction. J. Immunol. 46, 267.

Holloway, B. W. \& Monk, M. (1959). Transduction in Pseudomonas aeruginosa. Nature, Lond. 184, 1426.

$\mathrm{J}_{\mathrm{ACOB}}, \mathrm{F}$. (1955). Transduction of lysogeny in Escherichia coli. Virology, 1, 207. 
Krikler, M. S. (1953). The serology of Proteus vulgaris. Ph.D. Thesis: University of London.

Lamanna, C. \& Mallette, M. F. (1953). Basic Bacteriology, 1st ed. p. 404. Baltimore: The Williams and Wilkins Company.

LEDERBERG, J. (1951). Streptomycin resistance: A genetically recessive mutation. J. Bact. 61, 549.

LEnnox, E. S. (1955). Transduction of linked genetic characters of the host by bacteriophage P1. Virology, 1, 190.

LoutrT, J. S. (1959). Effect of ultraviolet irradiation on transduction in Pseudomonas aeruginosa. Nature, Lond. 184, 1960.

Morse, M. L., Lederberg, E. M. \& Lederberg, J. (1956a). Transduction in Escherichia coli K-12. Genetics, 41, 142.

Morse, M. L., Lederberg, E. M. \& Lederberg, J. (1956 b). Transductional heterogenates in Escherichia coli. Genetics, $41,758$.

Newcombe, H. B. \& Hawirko, R. (1949). Spontaneous mutation to streptomycin resistance and dependence in Escherichia coli. J. Bact. 57, 565.

Starlinger, P. (1958). Utber einen Defekt des transduzierenden Salmonella-Phagen P22. Z. Naturforsch. $13 b, 489$.

Stocker, B. A. D. (1956). Abortive transduction of motility in Salmonella; a nonreplicated gene transmitted through many generations to a single descendant. J. gen. Microbiol. 15, 575.

Stocker, B. A. D. (1959). Phage-mediated transduction. In Recent Progress in Microbiology, 1st. ed., p. 31. Ed. G. Tunevall. Oxford: Blackwell Scientific Publications.

Watanabe, T. \& Watanabe, M. (1959). Transduction of Streptomycin resistance in Salmonellla typhimurium. J. gen. Microbiol. $21,16$.

Zinder, N. D. \& Lederberg, J. (1952). Genetic exchange in Salmonella. J. Bact. 64, 679. 